\title{
Links Between Lateral Vegetation Zones and River Flow
}

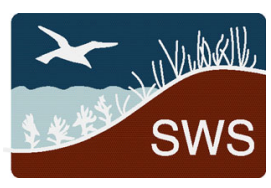

\author{
M. K. Reinecke • C. A. Brown • K. J. Esler • J. M. King • \\ M. T. Kleynhans $\cdot$ M. Kidd
}

Received: 4 July 2013 / Accepted: 22 January 2015 /Published online: 8 February 2015

(C) Society of Wetland Scientists 2015

\begin{abstract}
Plant species are known to be distributed on river banks in a sequence of community zones from the water's edge to the outer riparian area. The interplay between flow and landscape is thought to drive the existence of these zones, and specifically, between a lower zone that is inundated most
\end{abstract}

M. K. Reinecke $(\bowtie) \cdot$ C. A. Brown

Southern Waters Ecological Research and Consulting cc, PO Box

12414, Mill Street, 8010 Western Cape, South Africa

e-mail:karl@southernwaters.co.za

C. A. Brown

e-mail: cate@southernwaters.co.za

C. A. Brown · J. M. King

Institute for Water Studies, Department of Earth Sciences, University of the Western Cape, Private Bag X17, Bellville 7535, Cape Town, South Africa

J. M. King

e-mail: jackie.king@watermatters.co.za

M. K. Reinecke $\cdot$ K. J. Esler

Centre for Invasion Biology, Stellenbosch University, Private Bag

$\mathrm{X} 1$, Matieland, 7602 Stellenbosch, South Africa

K. J. Esler

e-mail: kje@sun.ac.za

\section{K. J. Esler}

Department of Conservation Ecology and Entomology, Stellenbosch University, Private Bag X1, Matieland, 7602 Stellenbosch,

South Africa

\section{T. Kleynhans}

Aurecon, Aurecon Centre, 1 Century City Drive, Waterford Precinct, Century City, South Africa

e-mail: martin.kleynhans@aurecongroup.com

\section{Kidd}

Centre for Statistical Consultation, Faculty of Accountancy and Statistics, University of Stellenbosch, Private Bag X1, Matieland, 7602 Stellenbosch, South Africa

e-mail: mkidd@sun.ac.za years and an upper zone that is inundated less frequently. There remains no consensus on the number of zones present, what their links to flow might be or whether the same zones occur in different basins. This paper reports on the number and nature of vegetation zones along South African rivers in different geographical areas and their relationship to the flow regime. River bank sites in four climatic areas of South Africa were found to support four vegetation zones (in two groups) despite major differences in vegetation community types, climate and patterns of river flow. The Wet bank and Dry Bank zones were separated at an elevation that correlated well with the 1:2 year flood line. If vegetation zones along rivers can be linked in this generic way to the flow regime of a river, it will strengthen our ability to predict vegetation changes likely to occur with flow modifications.

Keywords Flood recurrence $\cdot$ Inundation duration · Riparian zone

\section{Introduction}

There is a growing body of knowledge on the distribution and nature of vegetation along river banks and across floodplains. Naiman et al. (2005) reviewed much of this, describing how the vegetation changes with distance from the river's edge in a series of lateral zones. For both floodplains and river banks, the primary drivers of zonation are usually seen as two-fold. Arguably, the main one of these is river flow, with the magnitude and timing of flow (Poff et al. 1997), the area of land it inundates, and the velocity, depth and duration of inundation all influencing what plant species can live where. The geomorphological nature of the river channel and surrounding land is also important, as is the nature of the soils, dictating where water can reach and for how long. Through the interplay of flows and 
landscape, river banks are inundated and exposed at different times of the year, providing a range of conditions that are exploited by different plant species. Floodplains exhibit similar vegetation patterns, with their outer rims supporting quite different species to the middle and inner sections.

The main vegetation zones can be broadly characterised as a lower (or inner, on floodplains) one that is inundated most years and a higher (or outer) one that is inundated less frequently (Harris 1986; Hughes 1990; Hupp 1992). Some authors have divided these major zones into sub-zones. Hupp and Osterkamp (1996), for example, working across a spectrum of river types, described two communities within the lower zone that were inundated $c a .40$ and 5-25\% of the year, and two within the upper zone, one of which was flooded every 2-3 years and the other less frequently. Kemper and Boucher (2000) and Nilsson and Svedmark (2002) described the botanical nature of the two main zones along rivers: a lower zone of graminoids (sedges, rushes and grasses) and a higher zone of woody shrub and tree species many of which occur only or mainly along rivers. Several authors noted that the border between the two major zones appeared to be at the elevation reached by the channel-forming or bank-full flood, which has a return period of about 2 years in strongly perennial rivers, or longer in rivers with more flashy hydrographs.

Although many such findings have been reported, there is presently no consensus on how many zones there are and whether the same zones occur in different river basins. Additionally, the suggested links between zones and flow have not been empirically tested across a spectrum of conditions. In many cases this has been because of sampling bias in the different methods used, such as an a priori delineation of zones prior to sampling rather than a post-sampling delineation through data analysis. This paper addresses this knowledge gap, reporting on research to establish the number and nature of lateral zones along South African rivers in different climatic zones, the relationship of these vegetation zones with the patterns of flow (hydrographs), and the possible links to their elevation above, and distance from, the river channel.

Research on southern African riparian zones has focused largely on floodplain forests, reporting the same kinds of trends mentioned above (Hughes 1988; 1990; van Coller 1992; van Coller et al. 1997, 2000; Mackenzie et al. 1999 and Botha 2001). Each study reported that lateral zones existed and proposed that they could usefully be categorized by correlating the combined hydraulic and geomorphic factors of the river with the distribution of riparian plants. None related the zones to bank/ floodplain slope or specific flow variables, because of either the complexity of the floodplain mosaic or the inaccuracy/incompleteness of the hydrological records. In this paper, as a first step and for simplicity, the focus has been on single-thread alluvial channels. Such rivers have the capacity to sculpt their own bed, by shifting and sorting bed material during different flows, and so should provide a clearer picture of flow-zonation links than either bedrock rivers, where areas of inundation and plant growth may be more driven by the nature of the landscape, or floodplains, because of their complexity.

The two main lateral zones recognised elsewhere were first formally described for two southern African rivers (a summer-rainfall river in Lesotho and a winter-rainfall river in South Africa) by Boucher (2002). He named the zones a lower Wet Bank, with an upper limit at the height of the larger intra-annual floods, and a higher Dry Bank, with an upper limit at the 1:20 year flood line. Two subzones were recognised in the Wet Bank (from the water upwards: the Fringing Sedge and the Shrub/Willow subzones) and three in the Dry Bank (Lower Dynamic, Tree/ Shrub and Back Dynamic). Kleynhans et al. (2007) recognised three zones along South African rivers (from the bottom upwards - Marginal, Lower and Upper), all loosely linked to different magnitude flows, and Reinecke (2013) suggested from research on rivers in the Fynbos Biome of the western Cape in South Africa that there were four zones (Marginal, Lower Dynamic, Lower, Upper). His first two zones grouped within the Wet Bank and the latter two within the Dry Bank. The Lower Dynamic zone was thought to be too dry for the sedges and similar of the Marginal zone to survive, but flooded too often for trees and shrubs of the Dry Bank to establish. His four zones occurred repetitively and predictably across 18 sites on seven rivers in the Western Cape, and there was a suggested strong link with lateral distance from, and elevation above, the water's edge. The mostly annual inundations of the Wet Bank and the rarer inundation of the Dry Bank support the international findings on zonation.

Dollar and Rowntree (2003) proposed that geomorphologically the division between the two major zones is sustained by small annual/biannual floods that shape the active channel, and larger so-called catastrophic floods that re-set the wider macro-channel at time intervals of up to 20 years or more. The nature of the vegetation community in each zone reflects the life-history traits (recruitment, persistence, reproduction) of individual species, each with its different response to flow and/or inundation. Thus, it is suggested that zonation reflects the occurrence of groups of species that respond in the same way to prevailing allogenic (hydrogeomorphological) factors, with autogenic (plant induced) factors playing a secondary role (Francis 2006).

With this body of knowledge recognising the existence of riparian vegetation zones and the apparent links to flow, we investigated whether or not the pattern of four lateral zones shown for Fynbos rivers was evident in riparian areas in other parts of South Africa, and if the 1:2 and 1:20 year flood 
recurrence intervals are good predictors of the upper boundaries of the Wet and Dry Bank zones. Our hypotheses were:

- The same pattern of four vegetation zones is repeated on different rivers irrespective of differences in climatic zone and species composition.

- Areas that are inundated every 1-2 years will support two distinct Wet Bank communities (Marginal and Lower Dynamic). Inundation at this frequency is a good predictor of the extent of the Wet Bank.

- Areas that are inundated less often than every 1-2 years, by infrequent large floods, will support two distinct Dry Bank communities. Inundation at this frequency is a good predictor of the extent of the Dry Bank.

If vegetation zones along rivers (and across floodplains) can be strongly linked in this generic way to the flow regime of a river, then it will strengthen our ability to predict vegetation changes that are likely to occur with flow modifications such as those caused by dams. Such predictions form part of Environmental Flow Assessments and are vitally important when water resource decisions are made, especially in developing countries where millions of people use riparian natural plant resources for food, construction materials, shelter, crafts and firewood. Assessing development-driven changes to river flow, the potential impacts on the riparian zone and the implication to vulnerable riparian people is becoming an important component of environmental impact assessments. The greater the geographical coverage of the generalisations that can be made, the greater the likelihood that they can and will be validly used in decisions on water-resource developments.

\section{Methods}

\section{Site Selection}

Three study areas with perennial rivers were selected in South Africa with different flow regimes and vegetation communities: Lowveld Riverine Forest and Northern Mistbelt Forest along rivers with summer peak flow in the north east (Mpumalanga); Southern Afrotemperate Forest along rivers with aseasonal or early spring peak flow in the southern Cape; and Fynbos Riparian Vegetation along rivers with winter peak flow in the western Cape (Mucina and Rutherford 2006, Fig. 1).

In each area, rivers were selected with predominantly longitudinal flow and little lateral floodplain development (Gomi et al. 2002) to minimise the complexity of the hydraulic modelling required. Nine study sites were chosen from riparian areas with minimal disturbance. All were located close to gauging weirs that had reasonably accurate hydrological records that were greater than 30 years in length (Table 1).

\section{Vegetation Data Collection and Analysis}

On both banks at each site, vegetation data were collected in $10 \mathrm{~m}$-wide belt transects positioned perpendicular to flow. The transects reached from the boundary with the adjacent upland community through the entire riparian zone to the water's edge and up to the equivalent boundary on the opposite bank. The centre point $(5-\mathrm{m})$ of each transect was located along a surveyed cross-section used
Fig. 1 A map of South Africa with the four study areas, FRV $=$ Fynbos Riparian Vegetation, $\mathrm{SAF}=$ Southern Afrotemperate Forest, $\mathrm{LRV}=$ Lowveld Riverine Forest and NMF $=$ Northern Mistbelt Forest.

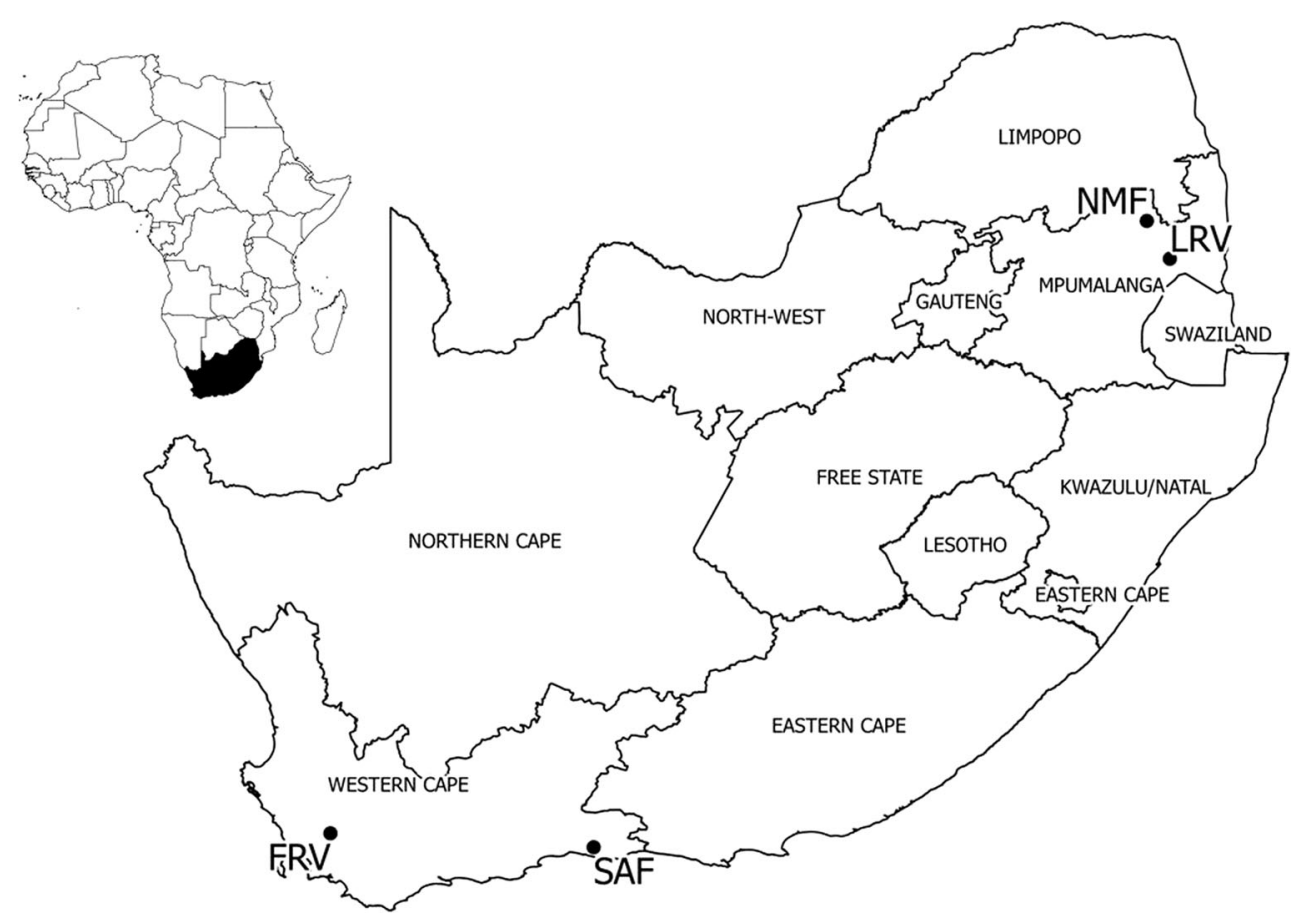


Table 1 Biophysical data and location of study sites. Zonation after Rowntree et al. (2000), vegetation community type from Mucina and Rutherford (2006)

\begin{tabular}{|c|c|c|c|c|c|c|c|}
\hline Vegetation Community & Region & River (Site code) & Latitude & Longitude & Gauge & Flow record & Geomorphic zone \\
\hline \multirow{3}{*}{$\begin{array}{l}\text { Fynbos Riparian } \\
\text { Vegetation }\end{array}$} & \multirow{3}{*}{$\begin{array}{l}\text { Western Cape (Winter high } \\
\text { flow, summer low flow) }\end{array}$} & Molenaars (Mol1) & -33.7233 & 19.17179 & Н1H018 & 1969 & Upper foothills \\
\hline & & $\begin{array}{l}\text { Elands } \\
\text { (Ela1) }\end{array}$ & -33.7392 & 19.1132 & H1H033 & $1991-$ & Transitional \\
\hline & & $\begin{array}{l}\text { Elands } \\
\text { (Ela2) }\end{array}$ & -33.7394 & 19.1131 & Н1H033 & $1991-$ & Transitional \\
\hline \multirow[t]{3}{*}{$\begin{array}{l}\text { Southern Afrotemperate } \\
\text { Forest }\end{array}$} & \multirow[t]{3}{*}{$\begin{array}{l}\text { Southern Cape (Aseasonal flow, } \\
\text { early spring peak) }\end{array}$} & $\begin{array}{l}\text { Karatara } \\
\text { (Kar1) }\end{array}$ & -33.8824 & 22.8385 & K4H002 & $1961-$ & Transitional \\
\hline & & Kaaimans (Kaa1) & -33.9711 & 22.5478 & К3H001 & $1961-$ & Transitional \\
\hline & & $\begin{array}{l}\text { Diep } \\
\text { (Die1) }\end{array}$ & -33.9136 & 22.7081 & K4H003 & $1961-$ & Upper foothills \\
\hline \multirow{3}{*}{$\begin{array}{l}\text { Lowveld Riverine Forest } \\
\text { Northern Mistbelt Forest }\end{array}$} & \multirow{3}{*}{$\begin{array}{l}\text { Mpumalanga (Summer high flow, } \\
\text { winter low flow) }\end{array}$} & Crocodile (Cro1) & -25.5024 & 31.1820 & Х2H032 & $1968-$ & Lower foothills ${ }^{\mathrm{a}}$ \\
\hline & & Mac Mac (Mac1) & -24.9999 & 30.8146 & X3H003 & $1963-$ & Upper foothills \\
\hline & & Mac Mac (Mac2) & -24.9999 & 30.8147 & Х3H003 & $1963-$ & Upper foothills \\
\hline
\end{tabular}

${ }^{a}$ This site on the Crocodile River did not meet the geomorphological criteria as it was lower down the longitudinal profile but was selected as it met the vegetation and hydraulic criteria better than all other sites visited in Mpumalanga

for hydraulic modelling (Fig. 2). Contiguous $1 \times 5 \mathrm{~m}$ plots were sampled all the way along the transect on both sides of the midpoint, except for Cro1 where the riparian zone was more than $100 \mathrm{~m}$ wide. Here, plots were sampled every $4 \mathrm{~m}$ on the left bank and every $2 \mathrm{~m}$ on the right bank, to arrive at the same number of plots on each bank as at the other sites $(\sim 12)$. The position of each plot was surveyed in along the cross-section. Species cover abundance was recorded for all visually present vascular species (Kent and Coker 1992) and for three life stages of

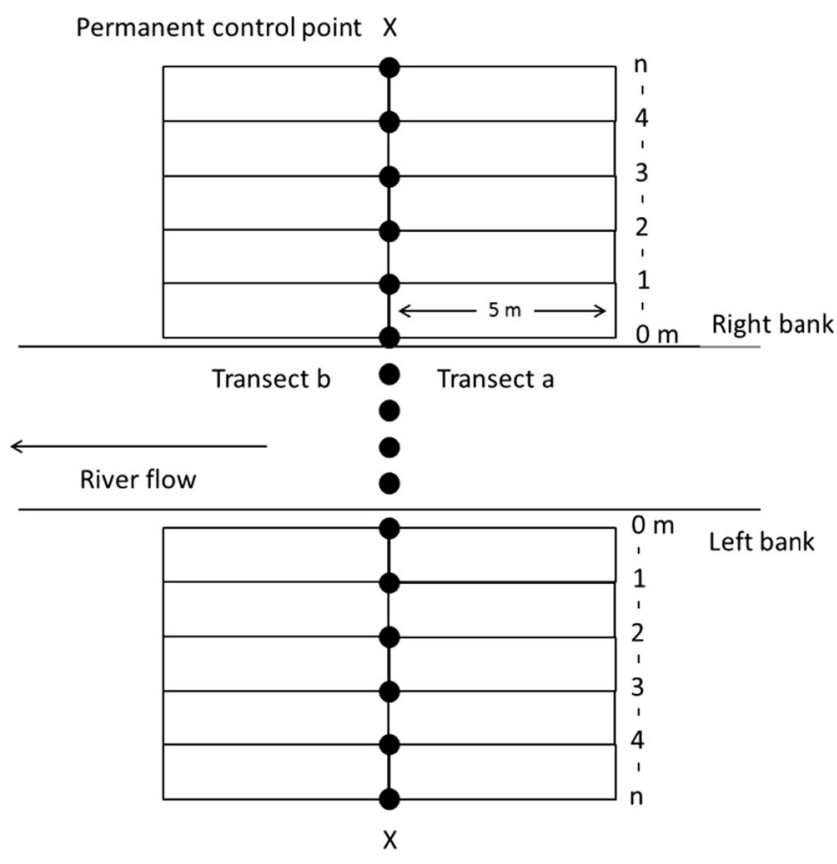

Hydraulic cross-section

Fig. 2 Study design employed at the nine study sites. Vegetation transects were aligned adjacent to hydraulic cross-sections on both river banks trees: seedling (height $<0.3 \mathrm{~m})$, sapling $(0.3>$ height $>2 \mathrm{~m})$ and tree (height $>2 \mathrm{~m}$ ).

Each species was assigned to one of three waterdependent categories based on its characteristic habitat as follows, using data on plant traits from Gibbs Russell et al. (1990), Pooley (1998), Goldblatt and Manning (2000) and Coates Palgrave (2002):

- species common on or near seeps, rivers and watercourses were deemed obligate riparian (wet) species;

- species described as occurring in bush, woodland or forests and/or associated with water courses were deemed facultative riparian (wet/dry) species.

- those occurring on rocky slopes and outcrops or mountain slopes were deemed incidental upland (dry) species.

Multivariate analyses (PRIMER V6, Clarke and Warwick 2006) were used to discern patterns of zonation at the species level. Data were 4th root transformed to better represent species with lower cover values. Bray-Curtis similarity coefficients were calculated between plots and the results were displayed using Multidimensional Scaling Ordinations (MDS) and CLUSTER analyses. Plots with greater than $40 \%$ similarity were tentatively recognised as groups, as were a few outlier clusters of plots with lower similarity. The significance of separation between groups was calculated using ANOSIM (analysis of similarities), a non-parametric permutation procedure analogous to ANOVA (Clarke and Gorley 2006). The SIMPER (similarity percentages) routine in PRIMER was used to discern typical and differentiating species between groups.

Groups of plots were assigned to lateral zones based on which water-dependent category most of their discerning species belonged to. 
Hydrological Data Collection and Analysis

Links between the vegetation plots along the transects and flood levels/inundation were explored using stage (water level) duration curves and flood-return intervals. Stage-duration curves were used to link the height of the water, and thus the duration of inundation, to positions on the hydraulic crosssections and to the grouped vegetation plots. Flood-return intervals indicate how often any specified magnitude flow occurs.

A time-series of daily average flows was obtained from DWA (2012) for the flow gauging station at each site. Data gaps of up to 20 continuous days in length, flagged as either missing or unreliable, were patched using mean monthly runoff ratios from nearby suitable DWA gauges. Years containing gaps longer than 20 continuous days were discarded from the record.

Flood-return intervals were determined by frequency analysis of daily average flow using annual maxima. It would also be possible to have used a partial-duration series, considered appropriate for short-return interval floods, but this carries the risk that floods may not be independent. Both these two methods should produce similar or equal results in terms of the size of the flood at longer return intervals (above about 10 years; Gordon et al. 2004). The annual maxima of daily average discharges were ranked and fitted to a Log Pearson III probability distribution. The greatest error for the flood peaks was estimated at $25 \%$ for the shortest record at a return period of 20 years (Linsley et al. 1975). For longer records at the other sites and for shorter return periods the errors were small$\mathrm{er}$, and it was possible, using hydrological records greater than 30 years in length, to estimate with reasonable accuracy how far up the transect $\mathrm{a}<20$ year flood will reach.

\section{Hydraulic Modelling}

Water levels of known discharge were surveyed in at each cross-section in September 2011, November 2011 and March 2012 at the western Cape sites; November 2011, April 2012 and June 2012 at the southern Cape sites, and April, June and July 2012 at the Mpumalanga sites. A stage-discharge rating curve was derived for each cross-section based on the surveyed water levels and observed flows by modelling additional high and low flow points and interpolating between these. The low flow point was surveyed in along the thalweg of the downstream hydraulic control, as the stage at which flow ceases, while the high flow end was chosen as the highest point along the hydraulic cross-section.

The higher flows were modelled using different approaches at different sites:

- For Ela1, Ela2, Kaa1, Kar1, Mac1 and Mac2: Manning's equation (Gordon et al. 1992) based on a single cross-section and representative high flow energy slope. Manning's $n$ values were estimated visually (Barnes 1967; Arcement and Schneider 1989; Hicks and Mason 1998; Birkhead and Desai 2009). The energy slope was measured off a 1:50 000 topographical map with $20 \mathrm{~m}$ contours and surveyed off the channel bed. The variation of Manning's resistance ${ }^{1}$ with stage was determined by plotting the Manning's resistances back-calculated from the observed stages, discharges and slopes.

- For Moll and Die1: A one-dimensional hydraulic model (HEC-RAS) consisting of at least three cross-sections and a downstream boundary condition consisting of:

- a surveyed downstream normal depth (slope) at Mol1; and

- a known rating curve for Die1 (DWA 2012).

The rating curves were determined by fitting Eq. 1 (Birkhead and James 1998) to the observed and modelled rating points determined above ${ }^{2}$ :

$y=a Q^{b}+\mathrm{c}$

- Cro 1: The cross-section and derived rating curve (Eq. 1) (Birkhead and Desai 2009), an ongoing monitoring site (DWA 2012), were used as the re-survey showed no significant changes since 2009 .

\section{Combining Hydrological and Hydraulic Data Sets}

Since the vegetation sample plots were $1 \mathrm{~m}$ in width and the river banks relatively steep, hydraulic modelling to achieve a horizontal accuracy of $0.1 \mathrm{~m}$ using the annual maximum series was considered reasonable. The rating curves were used to convert the time series of daily flows into stage at $0.1 \mathrm{~m}$ intervals along the transects reached by different magnitude flows. The stage duration curves provided the corresponding duration of inundation.

Because large or catastrophic floods often change the shape and nature of river channels and riparian zones, a shortened hydrological record was used for this exercise, consisting of the years since the last large flood:

- Mpumulanga: October 2000 to September 2011 (last large flood February 2000),

\footnotetext{
${ }^{1}$ Manning resistance $(n)$ is a composite factor that accounts for the effects of many forms of flow resistance. In general, $n$ increases as turbulence and flow retardation effects increase (Gordon et al. 1992).

${ }^{2}$ Where: (y) is stage, (Q) is discharge and (a), (b) and (c) are constants. (c) Denotes the depth of discharge cessation and thus is often zero in riffles where zero discharge occurs at zero depth, but non-zero in pools.
} 
- southern Cape: October 2008 to September 2011 (last large flood November 2007), and

- western Cape: October 2000 to September 2011 (last large flood June 1996).

\section{Relating Plant Distribution to Hydraulic Variables}

The vegetation zones were linked to the data on their height above the water (elevation), the regularity with which they would be inundated (exceedance probability, hereafter referred to as exceedance probability), and the inundation duration (length of time they would be inundated in days during a year \pm the standard deviation), using BEST (PRIMER V6, Clarke and Warwick 2006).

The relationship between exceedance probability (the reciprocal of which is recurrence interval) and inundation duration was tested using Least Squares Differential (LSD) tests in STATISTICA (V11, Statsoft, Inc 2013). Since each vegetation transect varied in length and comprised a different number of sample plots, and to avoid the bias of long transects, the same number of plots was selected for each transect. This was done by dividing each transect equally into five lengths and then randomly choosing vegetation plots from each for further analysis. The total number of plots chosen (18) was dictated by the number that the shortest transect yielded. For each plot, the analysis tested that each identified vegetation zone, as represented by its sample plots, had a cohesive set of hydraulic values that distinguished it from the other vegetation zones.

\section{Results}

Patterns of Lateral Zonation

Using the similarity guidelines explained earlier, four groups of vegetation plots could be discerned in most study rivers. With reference to the findings of Reinecke (2013) for western Cape Fynbos rivers, the following guide was used, for each river, to allocate its groups to a zone:

- groups that contained only incidental species were designated upland and were not considered further;

- groups containing a mixture of incidental and facultative species, and most closely related to the upland group were designated Upper zone;

- groups with facultative species were designated Lower zone;

- groups with a mixture of facultative and obligate species and that were most closely related to the Lower or Marginal groups were designated Lower Dynamic zone; and

- groups with obligate species were designated Marginal zone.
An example of the pattern of zones at a site is provided in Fig. 3.

All four named zones were present at 11 of the 18 sites: both banks of Mol1, Ela1, Kaa1, Die1, Cro1 and the left bank of Ela2. There was no Marginal zone on the right bank of Ela2, both banks of Kar1, Mac1 and Mac2, and no Lower zone on the left bank of Mac1. The Marginal zone was mostly missing where pools edged by large cobbles and boulders provided no footholds for the adventitious roots of Marginal-zone graminoids, which comprise a large proportion of the Marginal zone flora (Table 5). The Lower zone on the left bank at Mac1 was missing as the bank was almost vertical.

\section{Differentiating Species for Each Lateral Zone}

The Marginal zone was distinguished by a high cover of graminoids (sedges, rushes, reeds and grasses) and rhizomatous perennials, mostly ferns but also by palmiet Prionium serratum, in the Fynbos and southern Afrotemperate communities (Table 5). These species all shared traits associated with regular fluvial disturbance, such as reproducing both sexually and vegetatively, having a flexible habit and being able to resprout and anchor via adventitious root systems (Karrenberg et al. 2002). These coexisted with a low cover of pioneering trees, such as the Cape willow (Salix mucronata) on the Fynbos rivers, and the Matumi (Breonadia salicinia) on the Lowveld river.

The Lower Dynamic zone on the Fynbos rivers was distinguished by the common Restionaceae Calopsis paniculata that co-existed with the river heath Erica caffra. On the southern Afrotemperate rivers, it was represented by rhizomatous perennials Todea barbara and Dietes iridioides; on the Lowveld river by the grass Panicum maximum; and on the Northern Mistbelt river by the small tree Searsia batophylla along with a mixture of rhizomatous perennials and sedges. Trees and shrubs of the Lower Dynamic differed to those of the Marginal zones in predominantly reproducing sexually and having a tap and lateral root system, while graminoids of the Lower Dynamic tended to have a rhizomatous root. Many of the Lower Dynamic species retained the ability to re-sprout and were flexible, although not exclusively.

The Lower zone of the Fynbos rivers was distinguished by the tree Brachylaena neriifolia and the restio Elegia capensis. The Lower zones were distinguished in the southern Afrotemperate rivers by the grass Ehrharta rehmanii and the rhizomatous perennial Aristea ensifolia, and in the Lowveld river by the tree Bridelia cathartica and the shrub Phyllanthus reticulatus. The Northern Mistbelt river's Lower zones were represented by the rhizomatous perennial Chelianthes viridis and the shrub Leucosidea sericea. Plants of the Lower zone were less distinct with respect to traits. Graminoids and herbaceous perennials tended to retain the ability to re-sprout and were flexible in habit, while trees were not. 

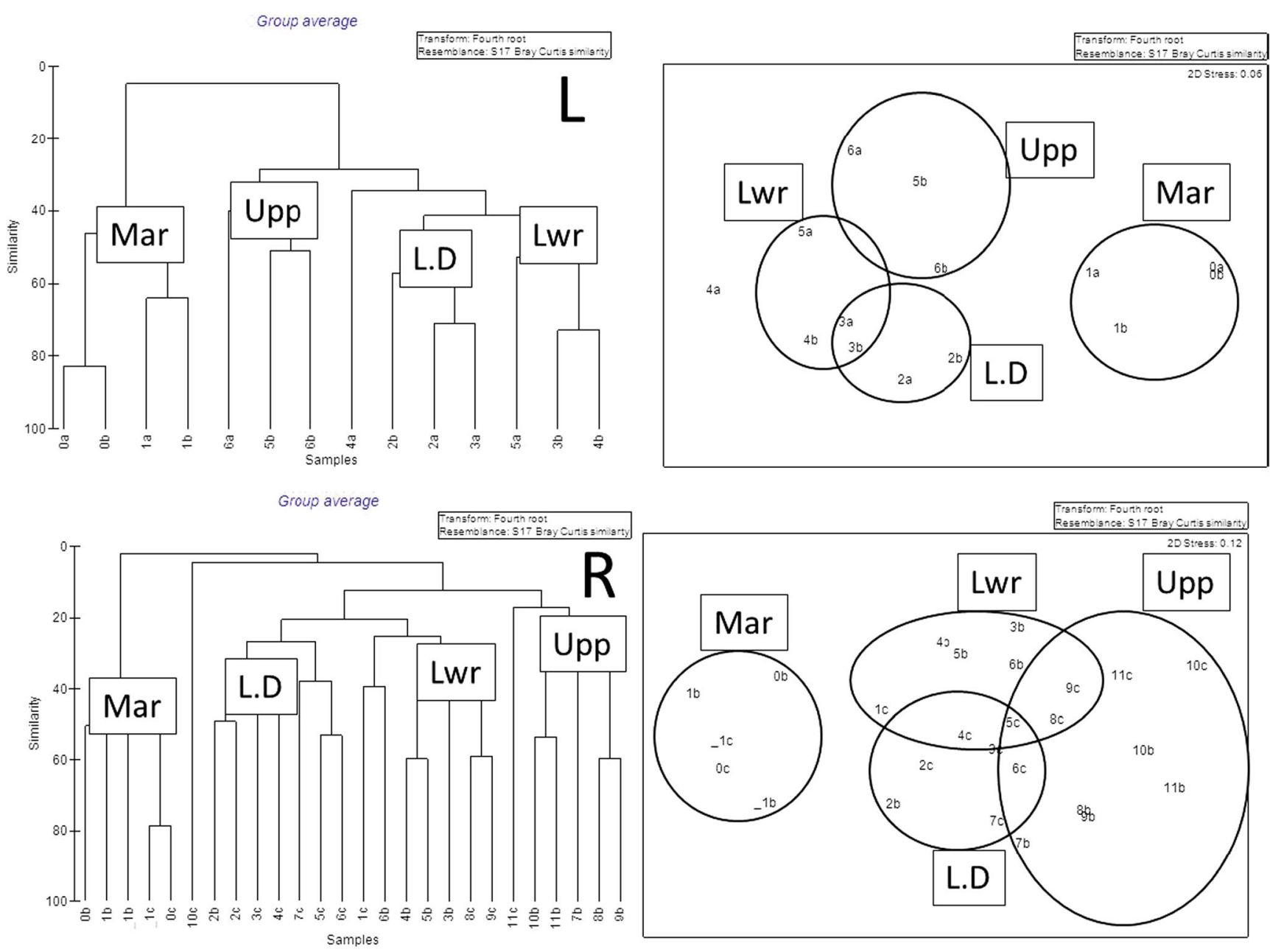

Fig. 3 CLUSTER analysis and MDS ordination of Bray Curtis similarity between sample plots on (L) the left and (R) right bank at Ela1. Mar = Marginal, L.D. = Lower Dynamic, Lwr $=$ Lower and Upp $=$ Upper.

The presence of upland species from the neighbouring communities adjacent to each site distinguished the Upper zone, characterised by a mixture of these with species from the Lower zone and other incidental species (see Table 5). At the Fynbos rivers the upper zone was distinguished by the shrubs Searsia angustifolia and Diospyros glabra with the rhizomatous perennial Pteridium aquilinum. The latter was also present in the Upper zone of the Northern Mistbelt rivers along with graminoids Setaria megaphylla and the tree Budleja sailvifolia. The southern Afrotemperate river's Upper zone was characterised by the rhizomatous perennials Blechnum punctulatum, Histiopteris incisa and the tree Searsia chirendesis while those of the Lowveld river were represented by the trees Canthium ventosum and Gymosporia senegalensis with the shrub Baleria elegans. All of these Upper zone plants are perennials and reproduce sexually post-flood, while the graminoids and herbaceous perennials also are able to reproduce vegetatively.

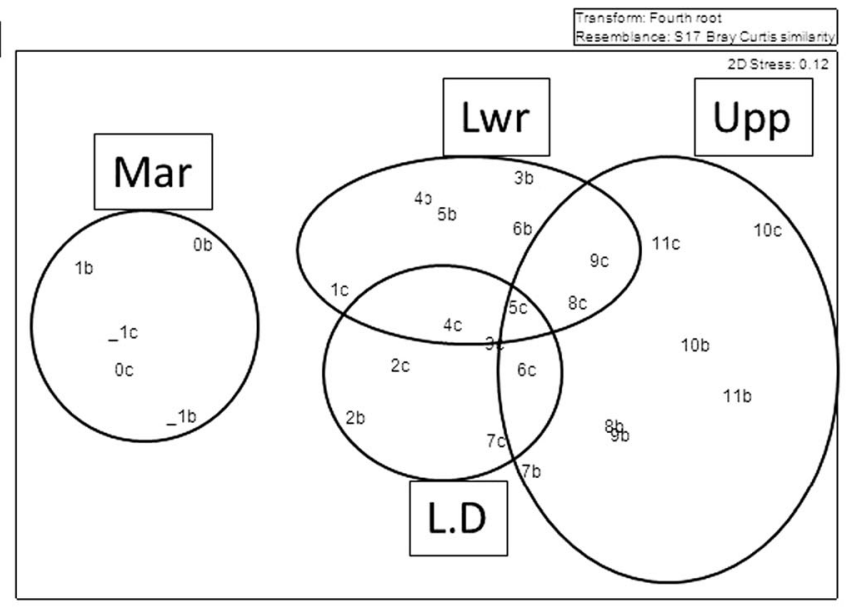

Similarity $=\%$ similarity between sample plots. Samples $=$ sample plot codes; $2 \mathrm{a}=$ metre 2 , transect $\mathrm{a}$

Hydraulics of Lateral Zones

River channel shapes were characterised by an active channel set within a macro-channel. A typical cross-section is shown in Fig. 4 for Ela1 where four flood-classes are illustrated along with the location of the four lateral zones. The rating curve for the same site is shown in Fig. 5, which was used to determine stage from discharge.

The distribution of plants correlated fairly well with the two main hydraulic variables: inundation duration and exceedance probability with $\mathrm{R}^{2}$ for both factors ranging between 0.4 and 0.7 . $\mathrm{R}^{2}$ values less than 0.3 represent a poor fit and are essentially meaningless.

The strongest correlation values were for a combined set of variables at all sites except for Kar1, Mac1 and Mac 2 (Table 2).

These three sites had their highest correlation values with the single variables elevation, inundation duration and exceedance probability, respectively. Nine of the combined relationships were strong $(>0.7)$, seven were fair $(0.4>x>0.7)$ and 
Fig. 4 Hydraulic cross-sections with the minimum observed annual flood, modelled inter annual floods that inundate each lateral zone and the upper limit of each vegetation zone at Ela1. WE = wetted edge of measured dry-season flow: lowest surveyed water level. Mar $=$ Marginal, L.D. $=$ Lower Dynamic, Lwr $=$ Lower, Upp $=$ Upper zones

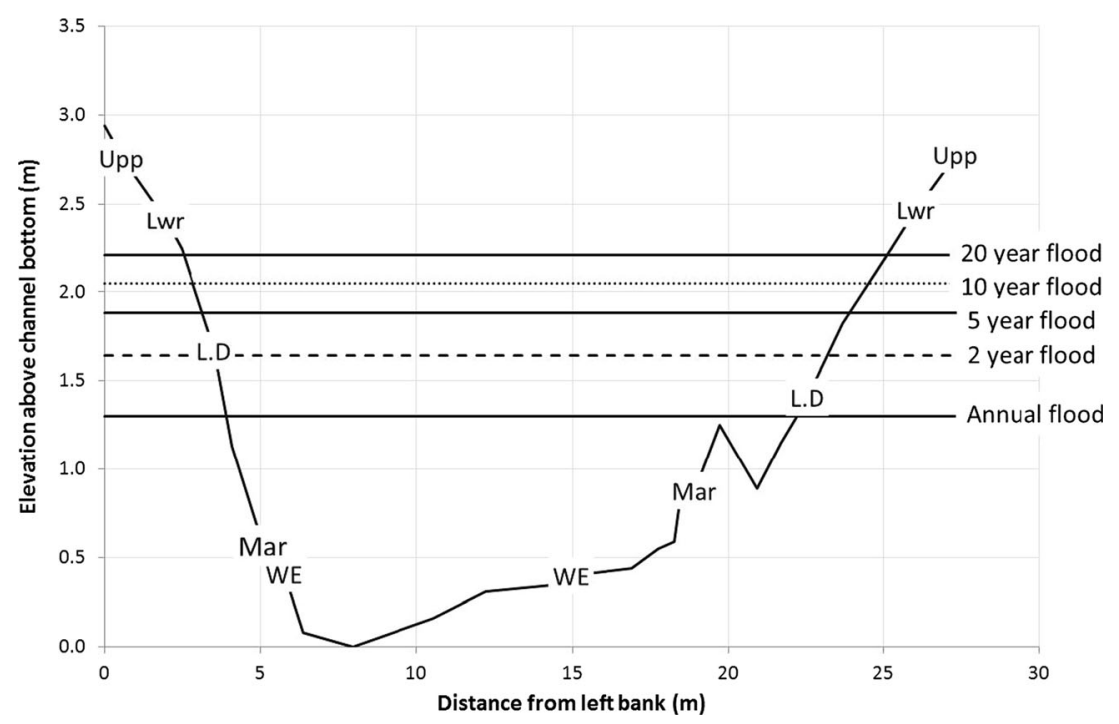

two were weak $(<0.4)$. The variables identified included distance and elevation vectors as well as the standard deviation about the mean inundation period.

Ten of the combined relationships were strong $(>0.7)$, six were fair $(0.3>x>0.7)$ and two were weak $(<0.3)$. Distance and elevation vectors were included as well as the standard deviation about the mean inundation period.

The relationships between vegetation zone type, flood recurrence intervals, exceedance probability and inundation duration, as represented by their mid-points on the cross-sections (Table 3), were different between the Marginal, Lower Dynamic and Lower zones.

The Marginal and Lower Dynamic were inundated by floods smaller than the 1:2 flood but for different periods. The Marginal zone was inundated between 97 and 203 days a year about an average of 150 days. The Lower Dynamic was inundated between one and 16 days a year about an average of eight days. The Lower zone was inundated by floods greater than the 1:2 year flood but was not distinguished from the other two by inundation duration.

The location of the Upper zone was not discriminated by any of the hydraulic variables tested.

\section{Discussion}

Four, or occasionally three, of the riparian vegetation zones described for Fynbos Riparian Vegetation (Reinecke 2013) were evident on all the rivers used in this study despite major differences in geographic location, vegetation community type, climate and patterns of seasonal flow. The zones correlated well with the magnitude of small to medium flood events. This concurs with studies from elsewhere in the world that report two Wet Bank zones inundated more or less
Fig. 5 Rating curve for Ela1, showing the measured and modelled data to which it was fitted using Eq. 1

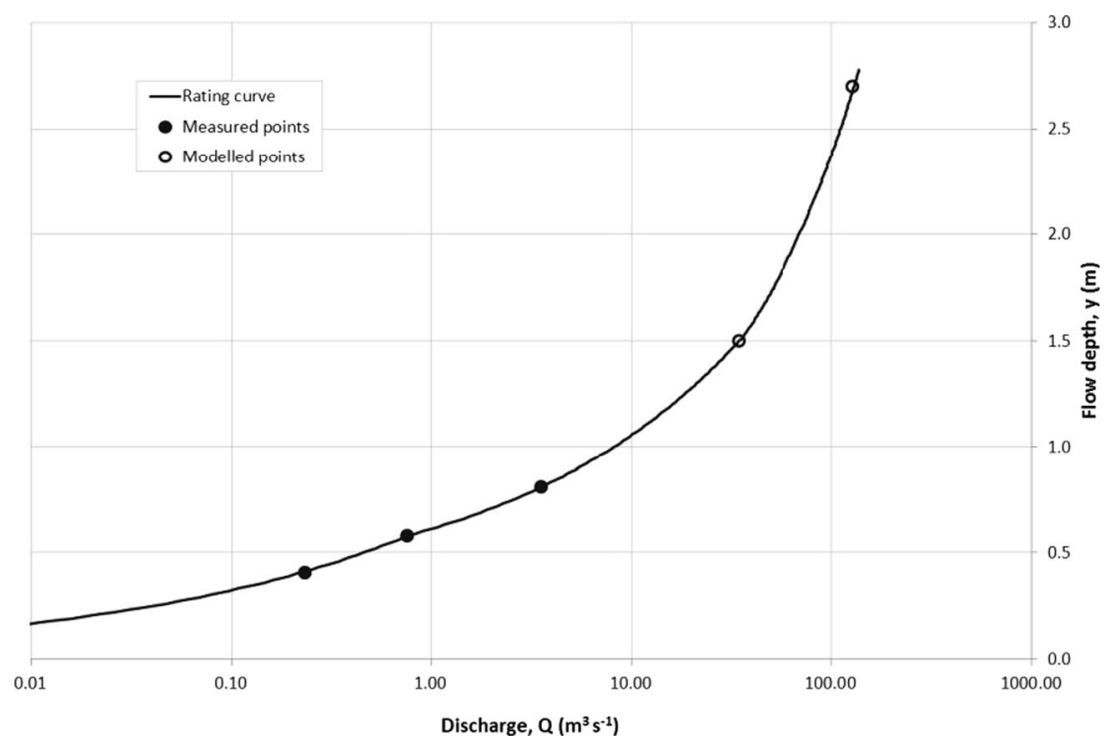


Table 2 BEST Correlations between plant distribution and inundation duration (I-D), standard deviation about this mean $(\delta \mathrm{I}-\mathrm{D})$ and exceedance probability (Ex. P)

\begin{tabular}{|c|c|c|c|}
\hline Community & Site & $\mathrm{R}^{2}$ & Factors \\
\hline \multirow[t]{6}{*}{ Fynbos Riparian Vegetation } & Mol1 LB & 0.537 & Distance, $\delta \mathrm{I}-\mathrm{D}$ \\
\hline & Mol1 RB & 0.631 & Distance, Ex.P \\
\hline & Ela1 LB & 0.825 & $\mathrm{I}-\mathrm{D}, \delta \mathrm{I}-\mathrm{D}$ \\
\hline & Ela1 RB & 0.639 & Distance, elevation, $\delta \mathrm{I}-\mathrm{D}$ \\
\hline & Ela2 LB & 0.707 & Elevation, Ex.P, I-D \\
\hline & Ela2 RB & 0.612 & Distance, elevation, Ex.P, $\delta \mathrm{I}-\mathrm{D}$ \\
\hline \multirow[t]{6}{*}{ Southern Afrotemperate Forest } & Kar1 LB & 0.698 & Elevation \\
\hline & Kar1 RB & 0.582 & Distance, Ex.P \\
\hline & Kaa1 LB & 0.846 & Distance, Ex.P \\
\hline & Kaa1 RB & 0.784 & Distance, Ex.P \\
\hline & Die1 LB & 0.777 & Distance, elevation, I-D, $\delta \mathrm{I}-\mathrm{D}$ \\
\hline & Die1 RB & 0.733 & Distance, elevation, I-D \\
\hline \multirow[t]{2}{*}{ Lowveld Riverine Forest } & Cro1 LB & 0.793 & Distance, Ex.P, $\delta \mathrm{I}-\mathrm{D}$ \\
\hline & Cro1 RB & 0.609 & Distance, elevation, Ex.P \\
\hline \multirow[t]{4}{*}{ Northern Mistbelt Forest } & Mac1 LB & 0.887 & $\mathrm{I}-\mathrm{D}$ \\
\hline & Mac1 RB & 0.383 & Distance, I-D \\
\hline & Mac2 LB & 0.870 & Ex.P \\
\hline & $\operatorname{Mac} 2 \mathrm{RB}$ & 0.369 & I-D \\
\hline
\end{tabular}

annually and two Dry Bank zones inundated at longer intervals (Harris 1986; Hupp and Osterkamp 1996; Nilsson and Svedmark 2002). Similarly, in southern Africa, Hughes (1990), Boucher (2002) and Kleynhans and Louw (2007a) proposed separating the riparian vegetation at the boundary of the annual flood.

Since no differences were reported for the inundation of the lower zone and the recurrence intervals of the upper (Table 3), all of the data in this study were used in one overall analysis to report averages for the main hydraulic variables: recurrence interval (RI), exceedance probability (Ex.P), inundation duration (I-D). This revealed that the four zones were clearly distinguishable by the frequency with which they were inundated and the number of days per year that this inundation persisted (Table 4). On average, using all of the plots in the whole of any one zone, the Marginal zone was inundated for about one quarter of the year, every year. The Lower Dynamic zone was inundated for about half a month over an approximate two

Table 3 Relationships between vegetation zones, recurrence interval (RI), exceedance probability (Ex.P), inundation duration (I-D), respective standard deviations $(\delta)$ and $95 \%$ confidence limits

\begin{tabular}{lllllllllll}
$\begin{array}{l}\text { Zone } \\
\text { RI } \\
\text { years }\end{array}$ & $\begin{array}{l}\text { Ex.P } \\
\%\end{array}$ & $\delta($ Ex.P) & -95 & +95 & $\begin{array}{l}\text { I-D } \\
\text { days }\end{array}$ & $\delta$ I-D & $-95 \%$ & $95 \%$ \\
\hline Mar & $1.1^{*}$ & $0.91^{*}$ & \pm 0.21 & 0.83 & 0.99 & $150^{*}$ & \pm 118 & 97 & 203 \\
L.D & $1.3^{*}$ & $0.75^{*}$ & \pm 0.22 & 0.61 & 0.89 & $8^{*}$ & \pm 12 & 1 & 16 \\
Lwr & $2.5^{*}$ & $0.37^{*}$ & \pm 0.37 & 0.21 & 0.53 & 6 & \pm 15 & 0 & 13 \\
\hline
\end{tabular}

Asterisked values are significant at the $5 \%$ level year cycle. These two zones are in the Wet Bank, and so the relationships support the contention that the 1:2 year flood line separates the Wet Bank from the Dry Bank. The 1:2 flood line division between Wet and Dry Banks has been noted in studies through South Africa, Zimbabwe, Lesotho, Mozambique, Tanzania, Peru, Namibia and Sudan (J. King, University of the Western Cape. pers. comm.)

The Lower zone was inundated for about one day every four years or so and the Upper zone very briefly and rarely, perhaps once a decade. Thus, higher up the bank, factors such as plant interactions (Silvertown et al. 1999; Francis 2006), or a higher groundwater table near the river, may have a greater influence on species distributions than normal river flows. Stochastic abiotic events, such as droughts, or very large floods that reset the entire riparian area by uprooting large trees and mobilising large volumes of alluvial sediments (Dollar and Rowntree 2003) may also help define the

Table 4 Average recurrence interval (RI), exceedance probability (Ex.P), inundation duration (I-D) and their respective standard deviations $(\delta)$ for each vegetation zone using all the plots designated to each zone from all sites

\begin{tabular}{llll}
\hline Vegetation zone & RI (years) & Ex.P $\pm \delta$ & I-D $\pm \delta$ (days) \\
\hline Mar & 1.2 & $0.85 \pm 0.18$ & $79.9 \pm 30.5$ \\
L.D & 1.5 & $0.67 \pm 0.34$ & $11.6 \pm 6.2$ \\
Lwr & 3.8 & $0.26 \pm 0.35$ & $1.2 \pm 0.4$ \\
Upp & 8.4 & $0.12 \pm 0.27$ & $0.1 \pm 0.1$ \\
\hline
\end{tabular}


nature of the Upper zone. Where large floods are absent, incidental species tend to establish in the higher parts of the riparian area, with possible cascading effects such as changes to the grazing patterns of large herbivores (Naiman et al. 2008). Althoug it is unlikely that floods of this magnitude contribute toward the separation of the zones, they can be responsible for eliminating upland species that become established there (Parsons et al. 2005) and have been shown to limit recruitment of invasives (Foxcroft et al. 2008).

In this study, the sequence of zones was not always complete, because of the valley shape and the nature of the substratum. At some sites, the lack of a Marginal zone may have been due to the absence of specialist riparian trees with pioneering attributes (Rood et al. 2005), such as Salix mucronata and Breonadia salicinia, which are able to root in the larger sediments (van Coller et al. 1997), or to the inability of finely rooted emergent graminoids (Koncalova 1990), such as rushes, sedges and reeds, to establish. In all cases, the relevant Marginal species did occur upstream or downstream of the site and were apparently absent from it because of the lie of the land or the nature of the bank particles.

The geographical variation in the species composition of the zones can mask the functional links with flow that were driving the creation of the zones. By categorising the species as obligate, facultative or incidental in terms of dependency on the river water, the same terms could be used across the study, showing that the functional nature of the vegetation in each zone was the same across all the sites regardless of geographic location (Fig. 6).

In general, adults of obligate riparian species occurred in the Marginal zone, those of facultative species in the Lower zone and those of incidental species mixed with facultative species in the Upper zone. Obligate species recruited into the Wet Bank, where seasonal wetting maintains soil moisture at levels conducive for this (Boucher 2002; Brown and King 2006). Facultative species were more widely distributed across the Wet and Dry Banks (Reinecke 2013). Incidental species recruited into the Upper zone rarely seemed to achieve adulthood, perhaps because they are unable to withstand the occasional flood inundation.

Reinecke (2013) demonstrated functional differences between some Wet Bank and Dry Bank trees in the western Cape in terms of their phenological and physiological adaptations. Wet Bank (obligate riparian species) trees were structurally flexible but broke easily, dispersing vegetative diaspores downstream, were able to re-sprout, and dispersed hydrochorous seed during low flow into the Marginal zone. Dry Bank (facultative riparian) trees were more tolerant to drying out, were less flexible structurally and dispersed seeds during high flow that were distributed more widely. In summary, in the winter-rainfall Fynbos Biome, the Wet Bank species tended to set seed in the dry season and the Dry Bank species in the wet season. It has not yet been assessed if this holds true elsewhere.

The distribution of functional types described here supports arguments for an ecohydrological basis for niche separation along a hydraulic gradient (Francis 2006). Categorising responses into functional types also supports the proposition by Merritt et al. (2010) to move away from species-level indicators for studies on environmental water requirements in favour of categories according to flow-linked life-history traits. Certainly, the results obtained in this study suggest that this

Fig. 6 Schematic of lateral zone distribution in relation to river flow. Large symbols are adults, small are saplings
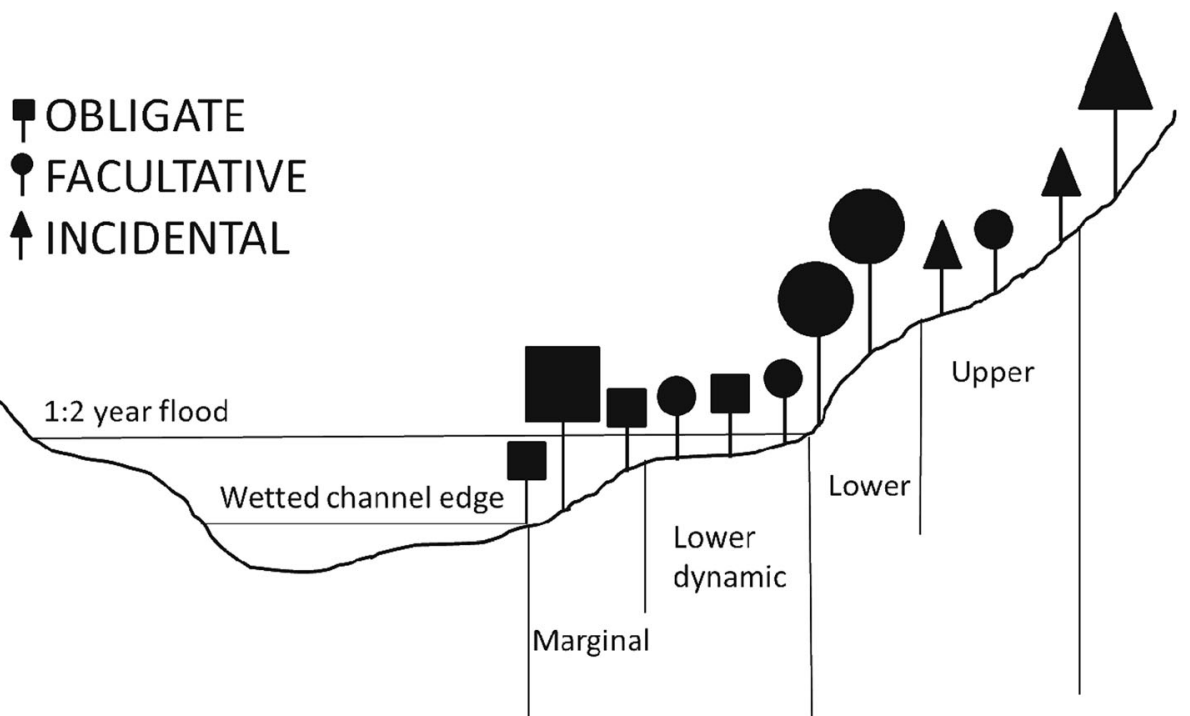

Aquatic
Wet bank
Terrestrial 
can be done, and indeed already is being done in southern Africa for rivers with and without floodplains (King et al. 2008).

Environmental flow assessments for rivers in the subcontinent identify vegetation zones and link these to inundation frequencies and duration to assess the present extent of each zone and how they would be affected by flow changes driven by water-resource developments. Zones may shrink or disappear as the flow regime changes and other zones expand, which could result in weakened, less stable banks (Karrenberg et al. 2002; Kotschy and Rogers 2008; Sieben and Reinecke 2008), greater invasion of alien species (Reinecke 2013), changes in biodiversity, a lower yield of plant species for subsistence users (Mbaiwa 2004) and an impact on large wild herbivores, particularly on floodplains, with repercussions through the trophic levels).

Recognising this, environmental flow assessments use the links between flow and vegetation zones to translate development-driven changes in flows into changes in the area of each vegetation zone. Predictions are then made on the biodiversity, social and resource economic implications. This provides stakeholders and decision makers with new insights as to how their river could change and supports more balanced and accountable decisions than was possible until recently.

There may be another interesting spin-off from work such as this. Where hydrological data are few, the demonstrated links between vegetation zones and flow could be used to either simulate or validate wet and dry season low flow discharge (using the Marginal zone); the magnitude and duration of the intra-annual floods (using the division between the Marginal zone and the Lower Dynamic zone); and the size of the 1:2 year flood, using the division between Wet and Dry Banks. Where there is a mismatch between hydrological data provided for an environmental flow assessment and the vegetation zones identified, the hydrological data have usually been proved to be at fault (Prof. C. Brown, UWC, pers. comm.). Thus the vegetation zones can provide a useful quality check of both the hydrological and hydraulic modelling done and may in some cases be able to partially replace them.

Acknowledgments The Water Research Commission for funding this study and Southern Waters Ecological Research and Consulting cc for logistic and office support. Dr Andrew Birkhead for directions to study sites and hydraulic data associated with these. 


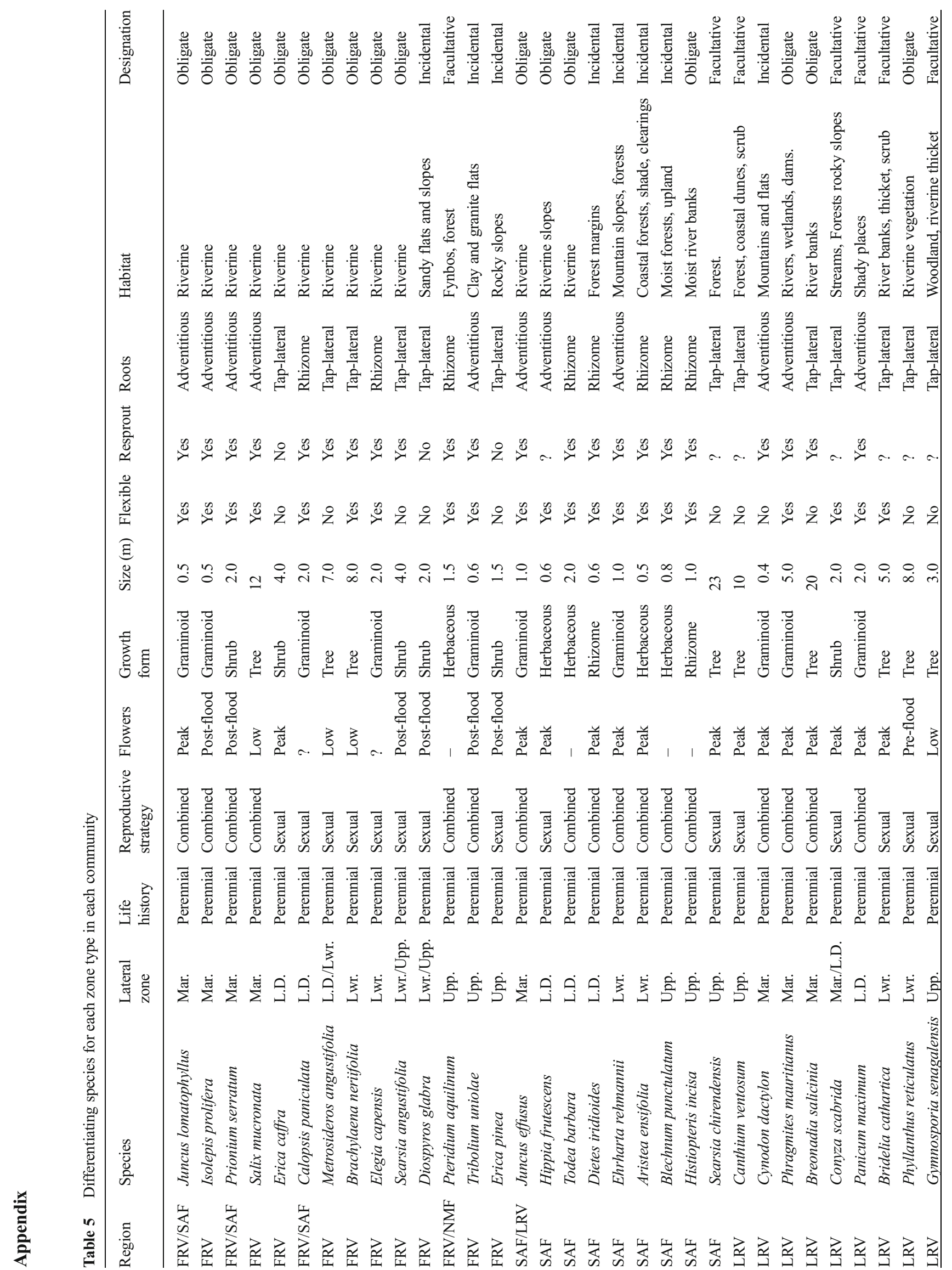




\section{References}

Arcement GJ. Jnr, Schneider VR (1989) Guide for selecting Manning's roughness coefficients for natural channels and flood plains, United States Geological Survey Water-Supply Paper 2339, Denver

Barnes HH (1967) Roughness characteristics of natural channels, United States Geological Survey Water-Supply Paper 1849, Denver

Birkhead AL, Desai AY (2009) Collation and synthesis of hydraulic information from environmental flow requirement studies. WRC KV 291/11. Water Research Commission, Pretoria, South Africa. $18 \mathrm{pp}$

Birkhead AL, James CS (1998) Synthesis of rating curves from local stage and remote discharge monitoring using nonlinear muskingum routing. Journal of Hydrology 205(1998):52-65

Botha M (2001) Dynamics of two South African flood plain forests. Water Research Commission, Pretoria, South Africa. WRC report No. KV 131/01. Water Research Commission, Pretoria, South Africa. $133 \mathrm{pp}$

Boucher C (2002) Flows as determinants of Riparian Vegetation zonation patterns in selected Southern African Rivers. Enviro Flows 2002 4th Ecohydraulics Conference, Cape Town, South Africa

Brown CA, King JM (2006) Implications of upstream water uses on downstream ecosystems and livelihoods. International Journal of Ecology and Environmental Sciences 32(1):99-108

Clarke KR, Gorley RN (2006) Primer V6: user manual/tutorial. Primer-E, Plymouth

Clarke KR, Warwick RM (2006) Change in marine communities: an approach to statistical analysis and interpretation, 2nd edn. PrimerE, Plymouth

Coates Palgrave KC, Coates Palgrave MC (2002) Trees of southern Africa, 3rd edn. Struik publishers, Cape Town

Department of Water Affairs (2012) Hydrological services - surface water (data, dams, floods and flows). http://www.dwaf.gov.za/ Hydrology/, accessed 20112012

Dollar EJS, Rowntree KM (2003) Geomorphological research for the conservation and management of southern African rivers. Volume 2: managing flow variability: the Geomorphological response. WRC Report no. 849/2/02. Water Research Commission, Pretoria, South Africa. 283pp

Foxcroft LC, Parsons M, McLoughlin CA, Richardson DM (2008) Patterns of alien plant distribution in a river landscape following an extreme flood. South African Journal of Botany 74:463-475

Francis RA (2006) Allogenic and autogenic influences upon riparian vegetation dynamics. Area 38(4):453-464

Gibbs Russell GE, Watson L, Koekemoer M, Smook LM, Barker NP, Anderson HM, Dallwitz MJ (1990) Grasses of Southern Africa. Memoirs of the Botanical Survey of South Africa No 58. National Botanical Gardens, South Africa

Goldblatt P, Manning J (2000) Cape Plants, a conspectus of the Cape flora of South Africa. Strelitzia 9, South African National Botanical Institute, Pretoria

Gomi T, Sidle RC, Richardson JS (2002) Understanding processes and downstream linkeages of headwater streams. BioScience 52(10): 905-916

Gordon, N.D., McMahon, T.A., Finlayson, B.L. (1992) Stream hydrology: an introduction for ecologists. John Wiley and Sons, West Sussex, England

Gordon ND, McMahon TA, Finlayson BL (2004) Stream hydrology: an introduction for ecologists. Wiley, West Sussex

Harris LD (1986) Occurrence patterns of riparian plants and their significance to water resource development. Biological Conservation 38: 273-286

Hicks DM, Mason PD (1998) Roughness characteristics of New Zealand Rivers: A handbook for assigning hydraulic roughness coefficients 
to river reaches by the "visual comparison" approach, Water Resources Survey, DSIR Marine and Freshwater, Wellington

Hughes FM (1988) The ecology of African floodplain forests in semi-arid and arid zones: a review. Journal of Biogeography 15(1):127-140

Hughes FM (1990) The influence of flooding regimes on forest distribution and composition in the Tana River floodplain, Kenya. Journal of Applied Ecology 17:475-491

Hupp CR (1992) Riparian vegetation recovery following stream channelization: a geomorphic perspective. Ecology 73(4):1209-1226

Hupp CR, Osterkamp WR (1996) Riparian vegetation and fluvial geomorphic processes. Geomorphology 14:277-295

Karrenberg S, Edwards PJ, Kollman J (2002) The life history of Salicaceae living in the active zone of floodplains. Freshwater Biology 47:733-748

Kemper N, Boucher C (2000) Riparian vegetation. In: Environmental Flow Assessments for rivers: manual for the building block methodology (updated edition). King, J.M., Tharme, R.E., de Villiers, M.S. (Eds). WRC report TT 354/08. Water Research Commission, Pretoria, South Africa. 339pp

Kent M, Coker P (1992) Vegetation description and analysis. Wiley, UK, $363 \mathrm{pp}$

King JM, Tharme RE, de Villiers MS (2008) Environmental Flow Assessments for rivers: manual for the building block methodology (updated edition). WRC report TT 354/08. Water Research Commission, Pretoria, South Africa. 339pp

Kleynhans, C.J., Mackenzie, J., Louw, D.A. (2007) Module F: Riparian vegetation response assessment index in River EcoClassification: Manual for EcoStatus determination (version 2). WRC report No. 329/08. Joint Water Research Commission and Department of Water Affairs and Forestry publication, Pretoria, South Africa

Kleynhans CJ, Louw MD (2007a) Module A: EcoClassification and EcoStatus determination in River EcoClassification: Manual for EcoStatus Determination (version 2). Joint Water Research Commission and Department of Water Affairs and Forestry report. WRC report No. TT 333/08

Koncalova H (1990) Anatomical adaptations to waterlogging in roots of wetland graminoids: limitations and drawbacks. Aquatic Botany 38 : $127-134$

Kotschy K, Rogers K (2008) Reed clonal characteristics and response to disturbance in a semi-arid river. Aquatic Botany 88:47-56

Linsley RK, Kohler MA, Paulhus JLH (1975) Hydrology for Engineers, 2nd edn, McGraw-Hill, New York., quoted in Gordon, N.D., McMahon, T.A, Finlayson, B.L., Gippel, C.J. and Nathan, R.J. 2004. Stream hydrology: an introduction to ecologists, 2nd edn, Wiley, Chichester

Mackenzie JA, van Coller AL, Rogers KH (1999) Rule based modeling for management of riparian systems. WRC report no. 813/1/99. Water Research Commission, Pretoria, South Africa. 156pp

Mbaiwa JE (2004) Causes and possible solutions to water resource conflicts in the Okavango River Basin: the case of Angola, Namibia and Botswana. Physics and Chemistry of the Earth 29:1319-1326

Merritt DM, Scott ML, Poff NL, Auble GT, Lytle DA (2010) Theory, methods and tools for determining environmental flows for riparian vegetation: riparian vegetation-flow response guilds. Freshwater Biology 55:206-225
Mucina L, Rutherford C (2006) The vegetation of South Africa, Lesotho and Swaziland. Strelitzia 19. South African National Biodiversity Institute, Pretoria

Naiman RJ, Decamps H, McClain ME (2005) Riparia. Ecology, conservation and management of streamside communities. Elsevier Academic Press, MA, 430

Naiman RJ, Latterell JJ, Pettit NE, Older JD (2008) Flow variability and the biophysical vitality of river systems. C.R. Geoscience 340:629-643

Nilsson C, Svedmark M (2002) Basic principles and ecological consequences of changing water regimes: riparian plant communities. Environmental Management 30:468-480

Parsons M, McLoughlin CA, Kotschy KA, Rogers KH, Rountree MW (2005) The effects of extreme floods on the biophysical heterogeneity of river landscapes. Frontiers in Ecology and the Environment 3(9):487-494

Poff NL, Allan MB, Bain JR, Karr KL, Prestegaard BD, Richter RE, Sparks RE, Stromberg JC (1997) The natural flow regime concept: a paradigm for river conservation and restoration. Bioscience 47: 769-784

Pooley E (1998) A field guide to the wild flowers of Kwa-Zulu Natal and the Eastern region. Natal Flora Publications Trust, Durban

Reinecke MK (2013) Links between lateral riparian vegetation zones and flow. Unpublished $\mathrm{PhD}$ thesis, Stellenbosch University, South Africa

Rood SB, Samuelson GM, Braatne JH, Gourley CR, Hughes FMR, Mahoney JM (2005) Managing river flows to restore floodplain forests. Frontiers in Ecology and the Environment 3(4):193-201

Rowntree KM, Wadeson RA, O'Keefe JO (2000) The development of a geomorphological classification systems for the longitudinal zonation of South African rivers. South African Geographical Journal 82(3):163-172

Sieben EJJ, Reinecke MK (2008) Description of reference conditions in restoration projects of riparian vegetation in the species rich fynbos. South African Journal of Botany 74(3):401-412

Silvertown J, Dodd ME, Gowing DJG, Mountford JE (1999) Hydrologically defined niches reveal a basis for species richness in plants. Nature 40(1):61-63

Statsoft, Inc (2013) STATISTICA (data analysis software system) version 12. www.statsoft.com

Van Coller, A.L. 1992. Riparian vegetation of the Sabie River: relating spatial distribution patterns to the physical environment. Unpublished M.Sc thesis, University of the Witwatersrand, Johannesburg, South Africa.

Van Coller AL, Rogers KH, Heritage GL (1997) Linking riparian vegetation types and fluvial geomorphology along the Sabie River within the Kruger National Park, South Africa. African Journal of Ecology 35:194-212

Van Coller AL, Rogers KH, Heritage GL (2000) Riparian vegetationenvironment relationships: complementarity of gradients versus patch hierarchy approaches. Journal of Vegetation Science 11:337-350

Van Ginkel CE, Glen RP, Gordon-Gray KD, Cilliers CJ, Muasya M, van Deventer PP. (2010) Easy identification of some South African Wetland Plants (grasses, restios, sedges, rushes, bulrushes, eriocaulons and yelloweyed grasses). Water Research Commission Report TT 479/10, Water Research Commission, Pretoria, South Africa. $390 \mathrm{pp}$ 